\title{
Risk factors for postoperative complications after fast-track abdominal hysterectomy
}

\author{
Lena Nilsson, Ninnie Borendal Wodlin and Preben Kjölhede
}

\section{Linköping University Post Print}

N.B.: When citing this work, cite the original article.

This is the authors' version of the following article:

Lena Nilsson, Ninnie Borendal Wodlin and Preben Kjölhede, Risk factors for postoperative complications after fast-track abdominal hysterectomy, 2012, Australian and New Zealand journal of obstetrics and gynaecology, (52), 2, 113-120.

which has been published in final form at:

http://dx.doi.org/10.1111/j.1479-828X.2011.01395.x

Copyright: Wiley-Blackwell

http://eu.wiley.com/WileyCDA/Brand/id-35.html

Postprint available at: Linköping University Electronic Press

http://urn.kb.se/resolve?urn=urn:nbn:se:liu:diva-76946 


\section{Risk factors for postoperative complications after fast track abdominal hysterectomy}

Short title: Fast track hysterectomy and complications

Lena NILSSON MD, PhD ${ }^{\mathrm{a}}$, Ninnie BORENDAL WODLIN $\mathrm{MD}^{\mathrm{b}}$ and Preben KJøLHEDE MD, $\mathrm{PhD}^{\mathrm{b}}$,

${ }^{a}$ Division of Drug Research, Anaesthesiology and Intensive Care, Department of Medical and Health Sciences, Linköping University. Department of Anaesthesia and Intensive Care, County Council of Östergötland, S - 58185 Linköping, Sweden

${ }^{b}$ Division of Obstetrics and Gynaecology, Department of Clinical and Experimental Medicine, Faculty of Health Sciences, Linköping University, Department of Obstetrics and Gynaecology, County Council of Östergötland, S - 58185 Linköping, Sweden

Corresponding author:

Lena Nilsson, $\mathrm{MD}, \mathrm{PhD}$

Department of Anesthesiology and Intensive Care

University Hospital

S-581 85 Linköping

Sweden

Phone+46101030000

Fax +46101032836

e-maillena.nilsson@lio.se

Alternative author:

Preben Kjølhede, MD, PhD

Department of Obstetrics and Gynaecology

County Council of Östergötland

S - 58185 Linköping

Sweden

Phone +46101030000

Fax +4613148156

e-mailpreben.kjolhede@liu.se

None of the authors has any conflict of interest to declare. The study was supported financially by grants from the Medical Research Council of South East Sweden; Linköping University and the County Council 


\section{Risk factors for postoperative complications after fast track abdominal hysterectomy}

Short title: Fast track hysterectomy and complications

Word count main text: 2492

Word count abstract: $\quad 249$

Keywords: postoperative complications; fast-track; hysterectomy; risk factors 


\begin{abstract}
Background: Fast track regimen has been shown to reduce postoperative complications in gastrointestinal surgery.

Aims: We investigated the incidence and type of postoperative complications and associated risk factors after benign abdominal hysterectomy undertaken in a fast track program.
\end{abstract}

Methods: A prospective longitudinal cohort study. In five Swedish hospitals a cohort of 162 women, ASA 1-2, undergoing abdominal hysterectomy in a fast track program was prospectively studied. Surgery was performed under spinal or general anaesthesia. The fast track concept was standardized with discharge criteria and a restricted intravenous fluid regimen. Complications were systematically registered during the 5-week followup period. Risk factors for complications were analysed using multiple logistic regression models.

Results: Forty-one (25.3\%) developed postoperative complications, mainly infection and wound healing complications. The majority of the complications developed after discharge and were treated in the outpatient clinics. Four women $(2.5 \%)$ were readmitted to hospital. Substantial risk factors for postoperative complications were obesity (OR 8.83), prior laparotomy (OR 2.92) and relative increase in body weight on the first postoperative day (OR 1.52).

Conclusions: Minor infection and wound healing complications seem to be common in healthy women undergoing abdominal hysterectomy in a fast track program. Obesity is an important risk factor also in fast track abdominal hysterectomy. A modest increase in postoperative relative weight gain during the first postoperative day seemed to increase the risk of postoperative complications. This factor merits further study. Randomized 
studies are necessary to determine the impact of fast track program and perioperative fluid regime on postoperative complications. 


\section{Introduction}

Hysterectomy is a common major benign gynaecological operation and is associated with significant postoperative morbidity ${ }^{1-3}$. There are several known risk factors for postoperative infectious morbidity, such as age, smoking habits, obesity, use of prophylactic antibiotics, duration of surgery, duration and use of transurethral catheter, duration of hospital stay and mode of hysterectomy ${ }^{2-6}$.

In the late 1990s, Henrik Kehlet introduced a multimodal approach of perioperative care for enhanced postoperative recovery, so called 'fast track' ${ }^{\text {, The }}$ concept comprises providing the patient with preoperative education concerning pre-, per- and postoperative care, optimizing anaesthesia, and management of pain and nausea, early postoperative mobilization and enteral nutrition with intravenous fluid restriction perioperatively ${ }^{8-10}$. A fast track regimen has been shown to reduce both the length of hospital stay ${ }^{11,12}$ and the number of postoperative complications ${ }^{8}$ in gastrointestinal surgery.

The fast track concept is often associated with perioperative intravenous fluid restriction. Fluid therapy may influence the postoperative course ${ }^{13}$. Hypovolemia is associated with the risk of tissue hypoperfusion and organ dysfunction, and hypervolemia may cause oedema and an increased risk of complications particularly from the cardiac, pulmonary and gastrointestinal systems. Increase in body weight postoperatively has actively been treated with diuretics ${ }^{13}$. A restrictive fluid regimen can reduce postoperative complications after major abdominal surgery ${ }^{13,14}$. There is limited information about fast track programs in gynaecological surgery ${ }^{15-17}$ and no information has been presented describing risk factors for postoperative complications after hysterectomy in a fast track setting. 
We have recently presented the results of a randomized trial "General anaesthesia versus Spinal anaesthesia with intrathecal morphine in fast track abdominal hysterectomy" (the "GASPI" study) with the primary objective duration of hospital stay $)^{17}$. The median duration of hospital stay was less than 50 hours ${ }^{17}$. The present study is a secondary post-hoc subgroup analysis of the participants in that trial. The aim of the present analysis was to investigate the incidence and nature of risk factors for postoperative complications after abdominal hysterectomy for benign gynaecological conditions in a fast track program. 


\section{Methods}

This prospective, multicentre cohort study of women undergoing subtotal or total abdominal hysterectomy for benign gynaecological disease was conducted in five hospitals in the southeast Health Region of Sweden. All the women in the cohort had participated in a previously presented randomized open controlled trial comparing the results of fast track abdominal hysterectomy under general anaesthesia with results under spinal anaesthesia ${ }^{17}$.The Regional Ethical Board at Linköping University approved the study. During the study period the trial underwent quality control by an independent monitor.

Inclusion criteria were: ASA 1-2 women aged 18-60 years with benign gynaecological disorders (cervical dysplasia and endometrial hyperplasia included). Exclusion criteria were: Former or planned concomitant bilateral oophorectomy, postmenopausal women without hormone therapy, gynaecological malignancy, morphine allergy, physically disabled, severe psychiatric or mental disorder and any condition contraindicating regional anaesthesia. The patients accepted participation in the study by signing informed consent.

Modes of hysterectomy and skin incision were decided on by the gynaecologist. All women received prophylactic antibiotics preoperatively. The content of the fast track program is summarized in Figure 1.

Surgery was performed under spinal or general anaesthesia. Both anaesthetic techniques were standardized. The hysterectomy was performed as a standard extrafascial hysterectomy according to the principles described by Thompson ${ }^{18}$. A transurethral urinary bladder catheter was inserted preoperatively and left until the next morning. 
Fig 1. Summary description of the fast track program and anaesthesia

\section{Preoperatively}

Thorough information concerning care anaesthesia, surgery and criteria for discharge.

Clear fluids orally until two hours before surgery. Two gram paracetamol orally one hour before surgery. No use of sedative. Antibiotic and antithrombotic prophylaxis according to department routine. Acupressure wrist bands applied preoperatively as pre-emptive antiemetic.

\section{Peroperatively}

Spinal anaesthesia with $20 \mathrm{mg}$ hyperbaric bupivacaine and $0.2 \mathrm{mg}$ morphine intrathecally. Sedation with propofol.

General anaesthesia induced with propofol, fentanyl and rocuronium, and maintained with propofol and oxygen in air. Rocuronium and fentanyl repeated when needed. Orogastric tube during surgery. Twenty minutes before ending the operation $5 \mathrm{mg}$ morphine injected iv.

Transurethral catheter inserted before start of surgery and left until next morning. $40 \mathrm{ml}$ bupivacaine $(2.5 \mathrm{mg} / \mathrm{ml})$ injected subcutaneously and pre-fascially in the abdominal wall at concluding surgery.

The total amount of intravenous fluids aimed at $25 \mathrm{ml} / \mathrm{kg}$ on day of surgery. Fenylephrine to treat hypotension if systolic blood pressure decreased $>30 \%$ from the baseline.

\section{Postoperatively}

Pain management with $1,330 \mathrm{mg}$ paracetamol and $50 \mathrm{mg}$ diclofenac three times daily. Additional pain management with morphine iv offered if VAS score $>3$ (VAS 0-10), but opioids avoided if possible.

Rescue antiemetic treatment with droperidol and if necessary combined with 5-HT3-receptor antagonist.

Patient encouraged to drink and eat as soon as possible and actively mobilized.

In gynaecological ward monitoring of haemodynamic and respiratory stability, sedation, pain, nausea and pruritus once every hour during first 12 hours postoperatively, then once every third hour for another 12 hours.

Standardized criteria of discharge.

iv $=$ intravenous. $\mathrm{PACU}=$ post anaesthesia care unit. $\mathrm{PONV}=$ postoperative nausea and vomiting. $\mathrm{VAS}=$ visual analogue scale 
We used a standardized restricted regimen of intravenous fluids perioperatively. The target for the total amount of intravenous fluids was set at $25 \mathrm{ml} / \mathrm{kg}$ per day, provided no complications had occurred. The patient was actively encouraged to drink and eat without restriction as soon as possible after surgery. Parenteral infusion was terminated on the morning of the day after surgery if the postoperative course was uneventful. Body weight was measured on the same scales preoperatively and on the morning after surgery. The calculation of change in body weight was adjusted for the weight of the removed uterus.

Postoperative pain management was based on paracetamol and diclofenac orally. Additional pain relief including morphine was offered on request.

The criteria for discharge of the patient were standardized. The patient had to be mobile, able to tolerate a normal diet, and be able to obtain sufficient pain relief with oral analgesics (VAS $\leq 4)$. She also must have voided spontaneously with less than 150 $\mathrm{ml}$ residual urine and show no signs of mechanical bowel obstruction. If the patient had urinary retention at discharge, she received a transurethral bladder catheter for another couple of days. The catheter was then removed in the out-patient clinic and the residual urine volume controlled ultrasonographically.

After discharge the woman was regularly contacted by telephone by the research nurse; initially the day after discharge and then once weekly until the 5-week follow-up visit at the hospital. If the participant showed or reported signs or symptoms of an overt or incipient complication during the hospital stay or at the telephone contacts she was referred to and examined by a doctor. In that way all per- and postoperative 
complications that occurred until 5 weeks postoperatively were systematically registered and classified.

Major complications were defined as: death, pulmonary embolism or deep venous thrombosis, all injuries to bladder, ureter or bowel, or to vascular structures such as the aorta, vena cava or iliac vessels, or any other reason making a re-operation necessary during the study period.

\section{Statistics}

No power calculations were done a priori for the outcome measures in this study. The power calculation of sample size in the "GASPI" study was based on the primary outcome, duration of hospital stay, and has been reported ${ }^{17}$.

Continuous data are expressed as median (range). Nominal data are presented as number (per cent). Univariate analyses were conducted by means of unadjusted logistic regression analyses and results reported as odds ratio (OR) and 95\% confidence interval (CI) and associated p-value. In order to analyse risk factors for postoperative complications multivariate analysis was performed by means of multiple logistic regression models. In these models adjustment was first carried out simultaneously for known and possible risk factors for postoperative infections and delayed wound healing (age, BMI, smoking habits, operation time, peroperative complications, duration of hospital stay, time with transurethral catheter and mode of hysterectomy). Subsequently, additional potential confounding factors were analysed in the above mentioned models by testing them one by one in order to evaluate the predictive value of these factors on the occurrence of postoperative complications. The results of the multiple logistic regression models are presented as ORs and 95\% CI and the corresponding p-value. The 
software StatView ${ }^{\circledR}$ for Windows, Copyright $@$, 1992-1998, Version 5.0.1 (SAS Institute Inc., SAS Campus Drive, Cary, NC 27513, USA) was used. 


\section{Results}

One-hundred and sixty-two women were included in the study. Forty-one women (25.3\%) developed one or more postoperative complications. The number and type of all per- and postoperative complications are shown in Table 1. Major complications occurred in six women $(3.7 \%)$.

Nine women (5.6\%) suffered per operative complications: four women had bleeding of $\geq 1000 \mathrm{ml}$ and one of them needed blood transfusion; three had bladder injury; one received blood transfusion due to low preoperative haemoglobin, and one had re-operation before ending anaesthesia due to retained surgical towels. Nine women (5.6\%) had postoperative complications during the hospital stay.

The majority ( $80 \%)$ of the postoperative complications developed after discharge from the hospital and all but four of these women were treated in the outpatient clinics. The four exceptions were readmitted to the hospital; two women had infected pelvic haematoma, one had a lower urinary tract infection, and one had a wound infection. These were all treated conservatively with antibiotics.

The most common complication was postoperative infections comprising over $60 \%$ of the complications. Commonplace wound-related complications such as wound infection, seroma, haematoma and superficial wound rupture constituted nearly $55 \%$ of the reported postoperative complications.

Possible risk factors for postoperative complications were divided into factors derived from demographic and preoperative clinical data (Table 2) and clinical measures (Table 3). Obesity (BMI $\geq 30 \mathrm{~kg} / \mathrm{m}^{2}$ ) was a strong independent risk factor for complications (OR 8.83). Women with earlier laparotomy were also at increased risk for postoperative complications. The length of time with transurethral catheter and duration 
of hospital stay were also significant but weak independent risk factors for postoperative complications.

The relative change in body weight on the first postoperative day was found to be an independent risk factor for complications (OR 1.52). The median relative change in body weight on the day after surgery was $0.5 \%$ in the subgroup of women that had any complication, and $0.3 \%$ in those without complications. This corresponds to an increase in body weight of 0.4 and $0.2 \mathrm{~kg}$, respectively.

In order to estimate the association between relative change in body weight (y) and amount of intravenous fluid given (x), a simple linear regression analysis was carried out. The analysis revealed a weak but statistically significant positive association between the two variables $\left(\mathrm{y}=-0.355+4.511 * 10^{-4} * \mathrm{x} ; \mathrm{R}^{2}=0.054 ; p=0.0044\right)$. Only three women (1.9\%) received intravenous fluids after the day of surgery: one due to reoperation, one with a vascular injury and heavy peroperative bleeding (3000 ml) and the third due to post-dural puncture headache. 


\section{Discussion}

This study showed that postoperative infection and wound healing complications were common and dominated the pattern of complications after fast track abdominal hysterectomy. Major complications were relatively rare with a rate comparable to that reported in a large Finnish study ${ }^{3}$. Although minor complications may be difficult to compare because of different definitions, the complications in the present study seem to be similar in type and frequency with those reported in other studies of benign abdominal hysterectomy carried out in non-fast track settings ${ }^{1,3}$. The study showed that obesity was a strong risk factor for postoperative complications even in a fast track setting. This agrees with results from other studies of benign abdominal hysterectomy ${ }^{3,4,6,19}$. Contrary to the finding presented by Brummer et al. ${ }^{3}$ we found that previous laparotomy was strongly associated with an increased risk of complications. Our finding is consistent with that of Nugent et al. ${ }^{20}$ who found that prior laparotomy was a very strong risk factor for wound complications in gynaecologic cancer surgery. Duration of hospital stay and length of time with urinary catheter were found to be weak significant risk factors for occurrence of postoperative complications. Duration of hospital stay and time with catheter were short in the fast track program, but although the median difference was only four hours and one hour, respectively, it was still significantly longer in the group of women who developed postoperative complications. Since all but one of the postoperative complications with infectious aetiology occurred after discharge from the hospital, one can speculate that there might be a causative association between a longer hospital stay and an increased risk of an acquired infection. Compared with results from other studies, the duration of hospital stay was a weak risk factor for developing postoperative complication ${ }^{6}$ as was catherization 
duration. This may reflect a possible effect of the fast track strategy and indicates that further shortening of the duration of these measures may have a limited effect on development of postoperative complications.

There are certain methodological limitations of the study. The "GASPI" study was designed and powered to compare differences in length of hospital stay ${ }^{17}$. The present report presents secondary analyses of data of the cohort that participated in the "GASPI" study. Sample size calculations were not done for these secondary objectives. The results should therefore be regarded as exploratory and hypothesis generating and consequently interpreted with precaution. An important strength of the study is that data were prospectively collected; the trial was conducted in accordance with good clinical praxis and was monitored by an authorized independent monitor. According to the study protocol, the intravenous fluid was aimed at $25 \mathrm{ml} / \mathrm{kg} / \mathrm{day}$ and this goal was achieved indicating good compliance with the protocol. These issues may increase the generalizability of the results.

The fast track regimen used in this study was strict in regulating the mode of anaesthesia, mode of prevention and treatment of postoperative nausea and vomiting (PONV), mode of pain treatment, and criteria for discharge ${ }^{17}$. We also included a standardized, restricted regimen for the perioperative volume replacement in order to avoid postoperative weight gain and facilitate postoperative oral intake as it has been proven advantageous in major abdominal surgery ${ }^{21}$. Brandstrup et al. demonstrated a dose-response relation between complications and increasing body weight after colorectal surgery ${ }^{13}$. We found an inappreciable increase in body weight on the morning after surgery in a group of otherwise healthy women undergoing abdominal hysterectomy but with a substantially lower increase in body weight. However, we did 
not measure the oral fluid intake or urinary output between surgery and weight control the day after surgery. The relative weight increase was associated with the occurrence of postoperative complications. The result could however be due to unknown confounders such as total fluid balance. We adjusted the results simultaneously for known and potential confounding factors. A possible interaction effect between these and unknown confounders may therefore not have been ruled out and the result should be interpreted with great caution

Only one postoperative complication was associated with major organ failure (pulmonary embolization). The complications were mainly infectious and haemorrhagic morbidity, and wound healing related problems, and thus are mainly associated with factors affecting the peripheral tissue. This may indicate that even minor changes in fluid balance may interfere with tissue homeostasis making the tissue more susceptible to infections and impaired healing. However, well designed studies are needed to rule out this question.

A fixed fluid regimen is unlikely to prevent both hypo- and hypervolemia in every single patient. An individualized "goal-directed" fluid regimen maximizing stroke volume with colloid boluses in major elective abdominal surgery has reduced complications and improved return of gastrointestinal function in randomized trials ${ }^{22,23}$. Until non-invasive non-costly alternatives of haemodynamic monitoring are available there is still a place for standardized fluid regimens in routine surgery on ASA 1-2 patients.

In the literature the change in body weight postoperatively is usually described in kilos $^{13,24-26}$. In order to describe possible fluid load it seems physiologically more correct to describe the relative weight gain. It is interesting to speculate about why some 
patients increased more in weight than others since we used a standardized fluid regimen based on weight. Although significant, we only found a weak positive correlation between intravenous fluid volume given and relative weight gain. Other factors must be involved in the explanation of the fact that some women increased in weight more than others.

In conclusion, minor postoperative complications, mostly infections and wound healing problems, seem to occur frequently after fast track abdominal hysterectomy and obesity, prior laparotomy, duration of hospital stay and time with catheter are risk factors. Even a minor postoperative weight increase indicating a perioperative fluid overload seems to increase the risk of postoperative complications. Further studies are necessary to determine the most optimal fluid regimen and monitoring for women undergoing major gynaecological surgery in fast track programs in order to reduce postoperative complications and thus enhance postoperative recovery. 


\section{Acknowledgements}

The study was supported financially by grants from the Medical Research Council of South East Sweden; Linköping University and the County Council of Östergötland. The physicians and research nurses in the multicentre study group are thanked for invaluable work and support. 


\section{References}

1. Nieboer TE, Johnson N, Lethaby A, et al. Surgical approach to hysterectomy for benign gynaecological disease. Cochrane Database Syst Rev. 2009 Jul 8;(3):CD003677. 1-191.

2. Mäkinen J, Johansson J, Tomás C, et al. Morbidity of 10110 hysterectomies by type of approach. Hum Reprod. 2001; 16: 1473-8.

3. Brummer TH, Jalkanen J, Fraser J, et al. FINHYST, a prospective study of 5279 hysterectomies: complications and their risk factors. Hum Reprod. 2011; 26: $1741-51$.

4. Löfgren M, Poromaa IS, Stjerndahl JH, Renström B. Postoperative infections and antibiotic prophylaxis for hysterectomy in Sweden: a study by the Swedish National Register for Gynecologic Surgery. Acta Obstet Gynecol Scand. 2004; 83: 1202-7.

5. Peipert JF, Weitzen S, Cruickshank C, Story E, Ethridge D, Lapane K. Risk factors for febrile morbidity after hysterectomy. Obstet Gynecol. 2004; 103: 8691.

6. Kjølhede P, Halili S, Löfgren M. The influence of preoperative vaginal scrub on postoperative infectious morbidity in abdominal total hysterectomy on benign indications. Acta Obstet Gynecol Scand. 2009; 88: 409-16.

7. Kehlet H. Multimodal approach to control postoperative pathophysiology and rehabilitation. Br J Anaesth. 1997; 78: 606-17.

8. Wilmore DW, Kehlet H. Management of patients in fast track surgery. BMJ. 2001; 322: 473-6. 
9. Kehlet H, Wilmore DW. Multimodal strategies to improve surgical outcome. Am J Surg. 2002; 183: 630-41.

10. Kehlet H. Fast-track colorectal surgery. Lancet. 2008; 371: 791-3.

11. Kehlet H, Wilmore DW. Evidence-based surgical care and the evolution of fasttrack surgery. Ann Surg. 2008; 248: 189-98.

12. Carter J, Szabo R, Sim, W, et al. Fast track surgery: a clinical Audit. Aust NZ J Obstet Gynaecol 2010; 50:159-63.

13. Brandstrup B, Tønnesen H, Beier-Holgersen R et al; Danish Study Group on Perioperative Fluid Therapy. Effects of intravenous fluid restriction on postoperative complications: comparison of two perioperative fluid regimens: a randomized assessor-blinded multicenter trial. Ann Surg. 2003; 238: 641-8.

14. Nisanevich V, Felsenstein I, Almogy G, Weissman C, Einav S, Matot I. Effect of intraoperative fluid management on outcome after intraabdominal surgery. Anesthesiology. 2005; 103: 25-32.

15. Møller C, Kehlet H, Friland SG, Schouenborg LO, Lund C, Ottesen B. Fast track hysterectomy. Eur J Obstet Gynecol Reprod Biol. 2001; 98: 18-22.

16. Kroon U-B, Rådström M, Hjelthe C, Dahlin C, Kroon L. Fast-track hysterectomy: A randomised, controlled study. Eur J Obstet Gynecol Reprod Biol. 2010; 151: 203-7.

17. Borendal Wodlin N, Nilsson L, Kjølhede P; GASPI study group. Fast track abdominal hysterectomy. The impact of mode of anaesthesia on postoperative recovery - a randomised clinical trial. BJOG. 2011; 118: 299-308. 
18. Thompson JD. Hysterectomy. In: Te Linde’s Operative Gynecology. Eds. Thompson JD, Rock JA. $7^{\text {th }}$ edition. Philadelphia. JB Lippincott Company, 1992. $687-706$.

19. Olsen MA, Higham-Kessler J, Yokoe DS, et al. Developing a risk stratification model for surgical site infection after abdominal hysterectomy. Infect Control Hosp Epidemiol. 2009; 30: 1077-83

20. Nugent EK, Hoff JT, Gao F, et al. Wound complications after gynecologic cancer surgery. Gynecol Oncol. 2011; 121: 347-52.

21. Joshi G. Intraoperative fluid restriction improves outcome after major elective gastrointestinal surgery. Anesth Analg. 2005; 101: 601-5.

22. Abbas SM, Hill AG. Systematic review of the literature for the use of oesophageal Doppler monitor for fluid replacement in major abdominal surgery. Anaesthesia. 2008; 63: 44-51.

23. Gan TJ, Soppitt A, Maroof M et al. Goal-directed intraoperative fluid administration reduces length of hospital stay after major surgery. Anesthesiology. 2002; 97: 820-6.

24. Lobo DN, Bostock KA, Neal KR, Perkins AC, Rowlands BJ, Allison SP. Effect of salt and water balance on recovery of gastrointestinal function after elective colonic resection: a randomised controlled trial. Lancet. 2002; 359: 1812-8.

25. Holte K, Kristensen BB, Valentiner L, Foss NB, Husted H, Kehlet H. Liberal versus restrictive fluid management in knee artroplasty; a randomized, doubleblind study. Anesth Analg. 2007; 105: 465-74. 
26. Holte K, Foss NB, Andersen J, et al. Liberal or restrictive fluid administration in fast-track colonic surgery: a randomized, double-blind study. Br J Anaesth. 2007; 99: $500-8$. 


\section{Figure legends}

Figure 1. Summary description of the fast track program and anaesthesia. 
Table 1. Number and type of per- and postoperative complications during hospital stay and 5 weeks postoperatively among 162 women who underwent fast track abdominal hysterectomy.

\begin{tabular}{|c|c|c|c|}
\hline Timing & Type of complication & Definition / description & Number $(\%)$ \\
\hline \multirow[t]{5}{*}{ Peroperatively } & Haemorrhage & Estimated blood loss $\geq 1000 \mathrm{ml}$ & $4(2.5 \%)$ \\
\hline & RBC transfusion & Transfusion due to peroperative haemorrhage or preoperative anaemia & $2(1.2 \%)$ \\
\hline & *Vascular injury & Accidental injury to internal iliac artery & $1(0.6 \%)$ \\
\hline & *Bladder injury & Accidental cystotomy & $3(1.9 \%)$ \\
\hline & ${ }^{*}$ Re-operation & Retained surgical towels discovered before end of anaesthesia & $1(0.6 \%)$ \\
\hline \multirow{8}{*}{$\begin{array}{l}\text { Postoperatively, } \\
\text { during hospital } \\
\text { stay }\end{array}$} & Intra-abdominal bleeding & Treated with tranexamic acid, desmopressin and RBC transfusion & $1(0.6 \%)$ \\
\hline & Re-operation & Due to a bladder injury detected on the first day postoperatively & $1(0.6 \%)$ \\
\hline & $\begin{array}{l}\text { Retroperitoneal and } \\
\text { subcutaneous emphysema }\end{array}$ & Suspicion of intra-abdominal infection, treated with antibiotics & $1(0.6 \%)$ \\
\hline & *Pulmonary embolism & Verified by CT scan and treated with anticoagulants & $1(0.6 \%)$ \\
\hline & Urticaria & Typical rash, requiring specific medication & $2(1.2 \%)$ \\
\hline & Post-dural puncture headache & Requiring specific medication and iv fluids & $1(0.6 \%)$ \\
\hline & Urinary retention & Requiring urinary catheter at discharge & $1(0.6 \%)$ \\
\hline & Cholecystolithiasis & Symptoms consistent with cholecystolithiasis, treated with NSAID & $1(0.6 \%)$ \\
\hline \multirow{9}{*}{$\begin{array}{l}\text { Postoperatively, } \\
\text { after discharge }\end{array}$} & Lower urinary tract infection & Verified by culture, clinical symptoms and treated with antibiotics & $9(5.5 \%)$ \\
\hline & Wound infection & $\begin{array}{l}\text { Includes infections in skin and subcutis and requires one of the following criteria: } \\
\text { 1. Purulent secretion from the wound } \\
\text { 2. Positive culture } \\
\text { If negative culture at least one of the following symptoms: Pain or tenderness; } \\
\text { local swelling; redness; warmth; wound opened superficially by physician }\end{array}$ & $14(8.6 \%)$ \\
\hline & Wound hematoma & $\begin{array}{l}\text { Hematoma localized to abdominal wall wound empties spontaneously or opened } \\
\text { superficially by physician }\end{array}$ & $1(0.6 \%)$ \\
\hline & Subcutaneous seroma & $\begin{array}{l}\text { Seroma localized to abdominal wall wound empties spontaneously or opened } \\
\text { superficially by physician }\end{array}$ & $5(3.1 \%)$ \\
\hline & Superficial wound rupture & $\begin{array}{l}\text { Skin and subcutis opened spontaneously and hematoma or seroma empties } \\
\text { spontaneously. No clinical signs of infection. }\end{array}$ & $1(0.6 \%)$ \\
\hline & Infected vaginal vault hematoma & $\begin{array}{l}\text { Localized infection in and around vaginal vault and treated with antibiotics and/or } \\
\text { debridement }\end{array}$ & $2(1.2 \%)$ \\
\hline & Vaginal vault hematoma & Spontaneously emptied or requires debridement or transfusion & $1(0.6 \%)$ \\
\hline & Pain/neuralgia & Prolonged neuralgic pain in the right hip and thigh & $1(0.6 \%)$ \\
\hline & Sore throat & Clinical signs of infection but negative culture & $1(0.6 \%)$ \\
\hline
\end{tabular}

*Events characterized as major complications. $\mathrm{CT}=$ computer tomography; NSAID = non-steroidal anti-inflammatory drug; RBC $=$ red blood cells. A woman may have more complications. 
Table 2. Demographic and preoperative clinical data of 162 women undergoing abdominal hysterectomy in a fast track model in relation to occurrence of postoperative complications.

\begin{tabular}{|c|c|c|c|c|c|c|c|}
\hline $\begin{array}{l}\text { Characteristics } \\
\text { Age (years) }\end{array}$ & & $\begin{array}{c}\text { Women with } \\
\text { postoperative } \\
\text { complication } \\
n=41\end{array}$ & $\begin{array}{c}\text { Women without } \\
\text { postoperative } \\
\text { complication } \\
n=121 \\
46(33-58)\end{array}$ & \multicolumn{2}{|c|}{$\begin{array}{c}\text { Univariate analysis }{ }^{\dagger} \\
\text { OR, } 95 \% \mathrm{Cl} \text { and } p-\text { value }\end{array}$} & \multicolumn{2}{|c|}{$\begin{array}{l}\text { Multivariate analysis }{ }^{\dagger \dagger} \\
\text { OR, } 95 \% \mathrm{Cl} \text { and } p-\text { value }\end{array}$} \\
\hline \multirow[t]{3}{*}{ BMI $\left(\mathrm{kg} / \mathrm{m}^{2}\right)$} & $\mathrm{BMI} \leq 25 \mathrm{~kg} / \mathrm{m}^{2}$ & $12(29.2 \%)$ & $62(51.2 \%)$ & 1 & -- & 1 & -- \\
\hline & $\mathrm{BMI}>25 \mathrm{~kg} / \mathrm{m}^{2}$ and $<30 \mathrm{~kg} / \mathrm{m}^{2}$ & $15(36.6 \%)$ & $40(33.1 \%)$ & $1.94(0.82-4.56)$ & 0.1303 & $2.38(0.83-6.84)$ & 0.1058 \\
\hline & $\mathrm{BMI} \geq 30 \mathrm{~kg} / \mathrm{m}^{2}$ & $14(34.1 \%)$ & $19(15.7 \%)$ & $3.81(1.51-9.62)$ & 0.0047 & $8.83(2.75-28.3)$ & 0.0003 \\
\hline \multirow[t]{4}{*}{ Indication of hysterectomy } & Bleeding disturbances & $25(61.0 \%)$ & $67(55.4 \%)$ & 1 & -- & 1 & -- \\
\hline & Mechanical symptoms & $14(34.1 \%)$ & $42(34.7 \%)$ & $0.89(0.42-1.91)$ & 0.7710 & $0.92(0.37-2.30)$ & 0.8617 \\
\hline & CIN//endometrial hyperplasia & $1(2.4 \%)$ & $8(6.6 \%)$ & $0.34(0.04-2.82)$ & 0.3140 & $0.45(0.04-4.47)$ & 0.4944 \\
\hline & Endometriosis/dysmenorrhea & $1(2.4 \%)$ & $4(3.3 \%)$ & $0.67(0.07-6.29)$ & 0.7259 & $1.56(0.13-19.2)$ & 0.7264 \\
\hline ASA & Class I & $26(63.4 \%)$ & $88(72.7 \%)$ & 1 & -- & 1 & -- \\
\hline Mode of skin incision & Midline & $5(12.2 \%)$ & $8(6.6 \%)$ & $1.96(0.60-6.38$ & 0.2625 & $1.18(0.26-5.46)$ & 0.8292 \\
\hline \multirow[t]{2}{*}{ Mode of anaesthesia } & General anaesthesia & $19(46.3 \%)$ & $61(50.4 \%)$ & 1 & -- & 1 & -- \\
\hline & Spinal anaesthesia & $22(53.7 \%)$ & $60(49.6 \%)$ & $1.18(0.58-2.39)$ & 0.6524 & $1.60(0.67-3.82)$ & 0.2932 \\
\hline \multicolumn{2}{|c|}{ Prior laparotomy (CS included) } & $21(51.2 \%)$ & $37(30.6 \%)$ & $2.38(1.16-4.92)$ & 0.0187 & $2.92(1.19-7.15)$ & 0.0192 \\
\hline
\end{tabular}

Figures denote median (range) or number (\%). BMI = body mass index; CIN = cervical intraepithelial neoplasia; CS = Caesarean section.

† Unadjusted logistic regression analysis.

${ }^{\dagger}$ Multiple logistic regression models adjusted for age, body mass index, smoking habits, mode of hysterectomy, operating time, peroperative complication, time with urinary catheter and duration of hospital stay. Statistically significant results in bold. 
Table 3. Clinical measures in relation to occurrence of postoperative complications in 162 women who underwent abdominal hysterectomy in a fast track model.

\begin{tabular}{|c|c|c|c|c|c|c|}
\hline \multirow{2}{*}{$\begin{array}{l}\text { Characteristics } \\
\text { Operating time (minutes) \# }\end{array}$} & \multirow{2}{*}{$\begin{array}{c}\begin{array}{c}\text { Women with } \\
\text { postoperative } \\
\text { complication } \\
n=41\end{array} \\
75(41-225)\end{array}$} & \multirow{2}{*}{$\begin{array}{c}\begin{array}{c}\text { Women without } \\
\text { postoperative } \\
\text { complication } \\
n=121\end{array} \\
75(40-173)\end{array}$} & \multicolumn{2}{|c|}{$\begin{array}{c}\text { Univariate analysis }{ }^{\dagger} \\
\mathrm{OR}, 95 \% \mathrm{Cl} \text { and } \mathrm{p}-\text { value }\end{array}$} & \multicolumn{2}{|c|}{$\begin{array}{c}\text { Multivariate analysis }{ }^{\dagger \dagger} \\
\text { OR, } 95 \% \mathrm{Cl} \text { and } p \text { - value }\end{array}$} \\
\hline & & & $1.00(0.99-1.01)$ & 0.6082 & $0.99(0.98-1.01)$ & 0.3773 \\
\hline Time of anaesthesia (minutes) \#\# & $120(90-266)$ & $115(60-210)$ & $1.01(1.00-1.02)$ & 0.2583 & $1.01(0.98-1.04)$ & 0.4652 \\
\hline Time in PACU (hours) & $4.2(2.0-23.0)$ & $3.8(1.5-14.2)$ & $1.12(0.96-1.31)$ & 0.1395 & $1.06(0.86-1.29)$ & 0.5915 \\
\hline Estimated blood loss peroperatively (ml) & $125(20-1500)$ & $100(0-3000)$ & $1.00(1.00-1.00)$ & 0.9223 & $1.00(1.00-1.00)$ & 0.3774 \\
\hline Uterus weight $(\mathrm{g})$ & $274(58-2096)$ & $317(41-2784)$ & $1.00(1.00-1.00)$ & 0.7719 & $1.00(1.00-1.00)$ & 0.8828 \\
\hline Time with transurethral catheter (hours) & $23(15-236)$ & $22(7-48)$ & $1.07(1.00-1.14)$ & 0.0469 & $1.07(1.01-1.13)$ & 0.0281 \\
\hline Duration of hospital stay (hours) \#\# & $51(22-125)$ & $47(24-80)$ & $1.04(1.02-1.06)$ & 0.0002 & $1.05(1.02-1.08)$ & 0.0005 \\
\hline Peroperative complication (no. of women) & $4(9.8 \%)$ & $5(4.1 \%)$ & $2.51(0.64-9.83)$ & 0.1870 & $0.22(0.02-2.93)$ & 0.2508 \\
\hline Transfusion of red blood cells (no. of women) & $1(2.4 \%)$ & $2(1.7 \%)$ & $1.49(0.13-16.95)$ & 0.7485 & $0.00(0.00-6944)$ & 0.4043 \\
\hline I.v. fluids given during hospital stay (ml) & $1975(1000-4000)$ & $1850(1000-10800)$ & $1.00(1.00-1.00)$ & 0.8337 & $1.00(1.00-1.00)$ & 0.9900 \\
\hline I.v. fluids given during hospital stay/kilo body weight (ml/kg) & $24.5(10.5-60.8)$ & $25.7(11.9-135.0)$ & $0.99(0.96-1.02)$ & 0.6461 & $1.00(0.97-1.04)$ & 0.8538 \\
\hline Change in body weight first postoperative day $(\mathrm{kg})$ \#\# & $0.4(-0.7-2.4)$ & $0.2(-1.9-3.4)$ & $1.45(0.98-2.16)$ & 0.0663 & $1.56(0.98-2.50)$ & 0.0624 \\
\hline Relative change in body weight first postoperative day (\%) \#\#\# & $0.5(-0.8-4.3)$ & $0.3(-2.3-4.2)$ & $1.35(1.01-1.81)$ & 0.0448 & $1.52(1.06-2.19)$ & 0.0223 \\
\hline
\end{tabular}

Figures denote median and (range) or number and (per cent). I.v. = intravenous. PACU = post anaesthesia care unit

${ }^{\dagger}$ Logistic regression analysis without adjustments.

${ }^{\dagger \dagger}$ Multiple logistic regression models adjusted for age, body mass index, smoking habits, mode of hysterectomy, operating time, peroperative complication, time with urinary catheter and duration of hospital stay.

" Time from skin incision to skin closed.

\#\# Time from start of anaesthesia to extubation (General anaesthesia) or leaving the operating room (Spinal anaesthesia).

\#\#\# Time from start of anaesthesia to discharge from the hospital

\#\#\#\# Adjusted for weight of uterus

Statistically significant results in bold. 